\title{
Modelling and Simulation of a Building Energy Hub ${ }^{+}$
}

\author{
Angel A. Bayod-Rújula 1,*, Yue Yuan 2 , Amaya Martínez-Gracia ${ }^{3}$, Jiangyu Wang ${ }^{4}$, Javier Uche ${ }^{3}$ \\ and Huanxin Chen ${ }^{4}$ \\ 1 CIRCE Institute, Department of Electrical Engineering, University of Zaragoza, 50009 Zaragoza, Spain \\ 2 China-Eu Institute for clean and Renewable Energy, Huazhong University of Science and Technology, \\ Wuhan 430074, China; m201671238@hust.edu.cn \\ 3 CIRCE Institute, Department of Mechanical Engineering, University of Zaragoza, 50009 Zaragoza, Spain; \\ amayamg@unizar.es (A.M.-G.); javiuche@unizar.es (J.U.) \\ 4 Department of Refrigeration \& Cryogenics, Huazhong University of Science and Technology, \\ 1037 Luoyu Road, Wuhan 430074, China; jywang_2016@hust.edu.cn (J.W.); \\ chenhuanxin@tsinghua.org.cn (H.C.) \\ * Correspondence: aabayod@unizar.es \\ + Presented at the International Research Conference on Sustainable Energy, Engineering, Materials and \\ Environment 2018, Mieres, Spain, 25-27 July 2018.
}

Published: 21 November 2018

\begin{abstract}
The development of technologies such as efficient multi-generation system, lead to realizing the benefits of integrated energy infrastructure such as electricity, natural gas, and heating networks, and thus a rapid movement toward multi-energy systems (MES). In such systems, different energy carriers and systems interact together in a synergistic way. An Energy hub (EH) can be defined as the place where the production, conversion, storage and consumption of different energy carriers takes place, is a promising option for integrated management of MES. In this work we present the hourly Schedule along a year of a building energy hub, with local generation of heat and power, energy storage and electrical and thermal loads. We include PVT systems and a CHP system in the local generation of heat and power, and a gas boiler. A battery is considered as electrical storage and a water tank as thermal storage. The system is connected to the mail grids of power and gas. The typical thermal and electrical load of a building has been considered, with a heat pump that is considered as a deferral load. The model for all the components has been developed, and a yearly simulation has been carried out in which prices of electricity and gas have been considered.
\end{abstract}

Keywords: energy hub; multi-energy systems; sustainable energy systems; PVT

\section{Introduction}

An energy hub can be regarded as an input-output unit model integrating energy conversion, energy transport, energy storage and load dissipation, see Figure 1 [1].

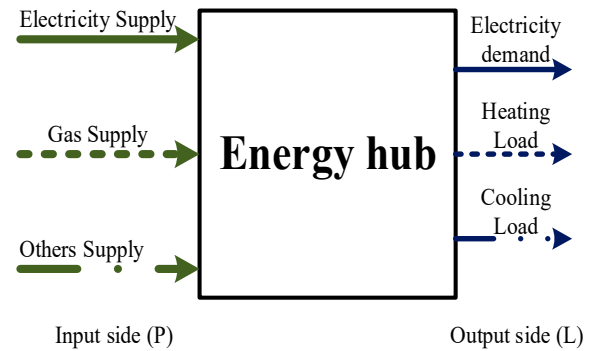

Figure 1. Energy hub definition. 
The basic mathematical model of energy hub system is

$$
L=f(P)
$$

In this formula, $L$ explicates the energy demand and $P$ demonstrates the power supply.

The basic matrix function of energy hub:

$$
\left[\begin{array}{c}
L_{1} \\
L_{2} \\
\vdots \\
L_{n}
\end{array}\right]=\left[\begin{array}{cccc}
c_{11} & c_{12} & \cdots & c_{1 m} \\
c_{12} & c_{22} & \cdots & c_{2 m} \\
\vdots & \vdots & & \vdots \\
c_{n 1} & c_{n 2} & & c_{n m}
\end{array}\right]\left[\begin{array}{c}
P_{1} \\
P_{2} \\
\vdots \\
P_{n}
\end{array}\right]
$$

In this expression, $c$ th is coupling factor, which represents the conversion efficiency between the $i$ th form energy input and the $j$ th form energy output.

Because energy hub has high abstract characteristics, no matter how heterogeneous a system is, it can be expressed in energy hub. In an energy hub model, there's a lot of flexibility about input resource, such as electricity from conventional grid, renewable energy or nuclear. In order to explore what renewable energy can be involved in a distributed energy source system. It is reasonable that in [2-5], energy hub was designed by using grid electricity, natural gas or renewable energy such as solar and wind energy. Besides, the energy hub output side represents customers' demand, which can be a known quantity. The energy saving, low economic cost and higher energy efficiency have been presented at the same time through running whole system under optimum operation rules [6-8].

\section{Case Study}

In this paper, a 3-storey residential building of $1660.73 \mathrm{~m}^{2}$ with 5 apartments per floor located in the city of Zaragoza (Spain) has been modeled for simulation (see Figure 2). Climate parameters of Zaragoza, including ambient temperature, solar irradiation and wind speed, have been taken from PVGIS database.

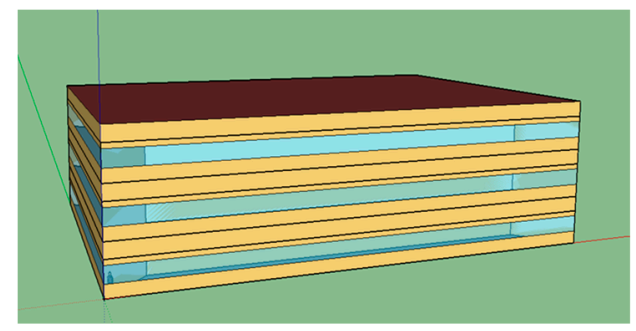

Figure 2. Simulation model in Energy plus.

The daily average energy consumption of the building for each month is shown as Figure 3, where blue bars represent the electricity consumption and the red curve represents the heat demand. Electricity demand include air conditioning consumption and heat demand includes heating and hot water demand. As shown in Figure 3, in August, building has the most electricity consumption and the lowest heating demand. The highest electricity demand can approach $220 \mathrm{kWh}$ per day and the highest heating demand is approximate $55 \mathrm{kWh}$ per day.

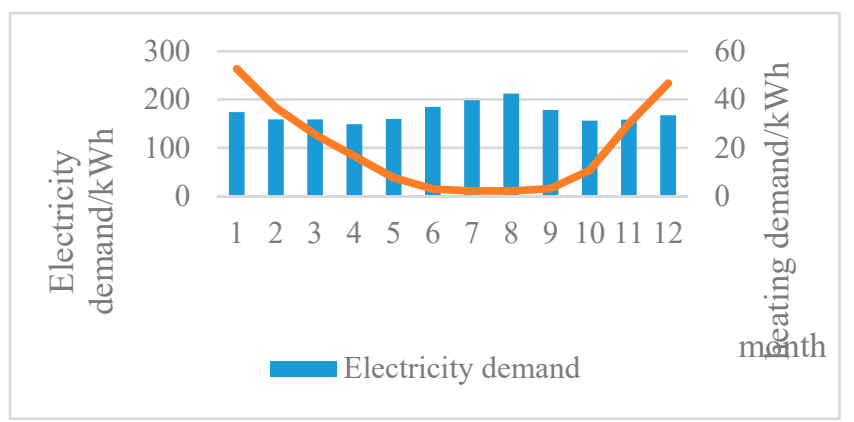

Figure 3. Daily energy consumption of simulation building each month. 
The electricity price is calculated by local actual-time price in Spain in 2017 (Figure 4). The gas price according to Spain actual gas price selected by 0.0667 Euro $/ \mathrm{kWh}$ and $0.0865 \mathrm{Euro} / \mathrm{kWh}$. To these values we have to add the taxes

Table 1 shows the total energy cost, $\mathrm{CO}_{2}$ emissions and consumptions of gas and electricity if we only rely on grid to satisfied electricity and heating demand of this building, the economic cost is $1.1713 \times 10^{4}$ Euro/year, being the total $\mathrm{CO}_{2}$ emissions $2.1711 \times 10^{4} \mathrm{~kg} /$ year. In this way, it not only caused amount of economic costs and greenhouse gas emissions, but also caused a considerable impact on the power grid during the electricity consumption peak period, increasing power grid maintenance cost.

Table 1. Energy consumption only supply by net.

\begin{tabular}{cccc}
\hline $\begin{array}{c}\text { Cost } \\
\text { (Euro/Year) }\end{array}$ & $\begin{array}{c}\mathrm{CO}_{2} \text { Emission } \\
(\mathbf{k g} / \text { Year) }\end{array}$ & $\begin{array}{c}\text { Gas Consumption } \\
(\mathbf{k W h} / \text { Year) }\end{array}$ & $\begin{array}{c}\text { Electricity Consumption } \\
\mathbf{( k W h} / \text { Year) }\end{array}$ \\
\hline $1.1713 \times 10^{4}$ & $2.1711 \times 10^{4}$ & $2.0518 \times 10^{4}$ & $6.2589 \times 10^{4}$ \\
\hline
\end{tabular}

Accordingly, it is necessary to build an energy hub model according to this simulation building, which aim to decline the cost, decrease greenhouse gas emissions, and meanwhile relief grid's pressure from peak load. In order to decrease economic cost of this building, heat pump (HP) and Photovoltaic plane (PV) introduced to constituent the energy hub HP is an equipment which can only take few electricity supply qualities of heating and cooling. Therefore, it's often considered as a significant component introduce in energy hub. The HP mentioned in this paper selected COP as 3.2. In order to get the optimized result, multiple simulation experiments have been conducted on the different capacity combination of this two components. Each component parameter includes capacity, efficiency, capital cost, fixed cost and variable cost is shown in Table 2. And $\mathrm{CO}_{2}$ emission from grid is shown in Table 3 respectively.

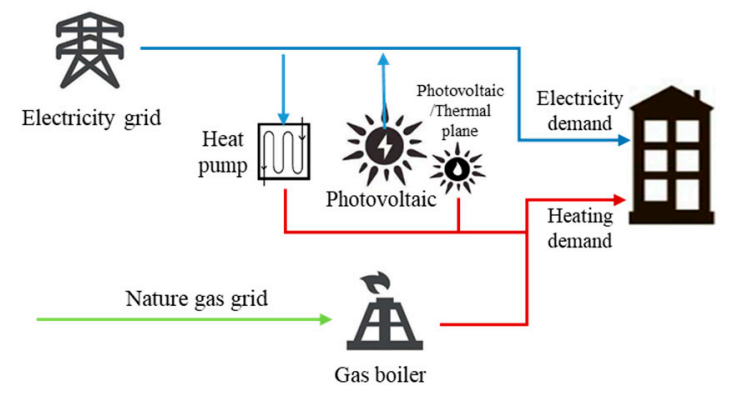

Figure 4. Single Building energy hub model.

In a conventional photovoltaic system, the conversion efficiency is approximate $15-20 \%$ generally. Part of unused solar energy will heat up the panel, causing efficiency and lifetime decline. It is obviously beneficial to collect thermal energy from solar while generating electricity from sunlight. This hybird system, which produces electricity and hea simultaneously is called Photovoltaic/Thermal (PV/T system).

The thermal part of PV/T system efficiency $\eta$ is influenced by many factors, such as solar irradiation, pipe fluid temperature and so on, which can be represented as Equation (3).

$$
\eta=\eta_{0}-a_{1} \times \frac{\left(T_{e}-T_{a}\right)}{G}-a_{2} \times \frac{\left(T_{e}-T_{a}\right)}{G}
$$

In this equation, $\eta_{0}$ means the optical performance of the PV/T system. $a_{1}$ and $a_{2}$ are the thermal losses coefficients, in this paper set as $3.3\left(\mathrm{~W} / \mathrm{m}^{2}\right) / \mathrm{K}$ and $0.018\left(\mathrm{~W} / \mathrm{m}^{2}\right) / \mathrm{K}^{2}$ respectively. I represents solar irradiation. $T_{e}$ is average value of pipe fluid temperature and $T_{a}$ is ambient temperature.

The annual cost of energy hub is comprised by 3 parts. Electricity from grid, gas from net and components cost, at the meantime components cost include average installation cost, operation and management annual fee, which shown as Equation (4). 


$$
\begin{aligned}
& \sum_{t=1}^{T}\left[P_{\text {ele }}(t) \times \text { electricityprice }+P_{\text {gas }}(t) \times \text { gasprice }\right] \\
& +\sum_{n=1}^{N}\left(\text { Component }_{\text {install }}+\text { Component }_{\text {o\&M }}-\text { Component }_{\text {discount }}\right)
\end{aligned}
$$

Table 2. Energy hub component parameters.

\begin{tabular}{cccc}
\hline Component & Efficiency & Capital Cost & Lifetime \\
\hline Gas Boiler & $70 \%$ & 800 Euro $/ \mathrm{kW}$ & 20 \\
Heat Pump & $3.2($ average COP) & $1000 \mathrm{Euro} / \mathrm{kW}$ & 20 \\
PV & $17 \%, \mathrm{PR}=0.8$ & $1500 \mathrm{Euro} / \mathrm{kW}$ & 30 \\
PVT & variable & $700 \mathrm{Euro} / \mathrm{m} 2$ & 30 \\
\hline
\end{tabular}

Table 3. Other parameters.

\begin{tabular}{cc}
\hline Name & Value with Unit \\
\hline $\mathrm{CO}_{2}$ emission from grid electricity & $0.280 \mathrm{~kg} / \mathrm{kWh}$ \\
$\mathrm{CO}_{2}$ emission from natural gas & $0.204 \mathrm{~kg} / \mathrm{kWh}$ \\
\hline
\end{tabular}

The result shown as Tables 4 and 5, while operating with $20 \mathrm{~kW} \mathrm{HP}$ and $65 \mathrm{~m}^{2} \mathrm{PV}$, the economic cost reach the minimum value $1.0727 \times 10^{4}$ Euro/year. The $\mathrm{CO}_{2}$ emission achieve $1.356 \times 10^{4} \mathrm{~kg} /$ year at the meantime. Compared to supply all electricity and heating from grid, $8.42 \%$ economic cost will be saved and reduce $37.54 \% \mathrm{CO}_{2}$ emission. We can illustrate that introduce suitable capacity of $\mathrm{HP}$ and PV system can cut cost and reduce carbon emission simultaneously. With more renewable energy participant into the hub, the lower $\mathrm{CO}_{2}$ emission energy hub system will achieve. So, the $\mathrm{CO}_{2}$ emission can't obtain the minimum value with economic cost at same time.

Table 4. Annual Cost for single building under Different PV and HP capacity $\left(\times 10^{4}\right.$ Euro/year).

\begin{tabular}{ccccccccc}
\hline & \multicolumn{7}{c}{ HP Capacity $\mathbf{( k W )}$} \\
\hline & & $\mathbf{0 . 5}$ & $\mathbf{1}$ & $\mathbf{5}$ & $\mathbf{1 0}$ & $\mathbf{2 0}$ & $\mathbf{2 5}$ & $\mathbf{3 0}$ \\
\cline { 2 - 9 } & 5 & 1.1514 & 1.1378 & 1.1220 & 1.0984 & 1.0953 & 1.1005 & 1.1090 \\
& 10 & 1.1468 & 1.1333 & 1.1175 & 1.0939 & 1.0908 & 1.0960 & 1.1045 \\
& 20 & 1.1402 & 1.1266 & 1.1108 & 1.0872 & 1.0841 & 1.0893 & 1.0978 \\
PV Capacity $\left(\mathrm{m}^{2}\right)$ & 30 & 1.1363 & 1.1226 & 1.1068 & 1.0832 & 1.0801 & 1.0853 & 1.0938 \\
& 50 & 1.1309 & 1.1173 & 1.1014 & 1.0778 & 1.0747 & 1.0799 & 1.0884 \\
& 60 & 1.1295 & 1.1158 & 1.0998 & 1.0762 & 1.0731 & 1.0783 & 1.0868 \\
& 65 & 1.1295 & 1.1157 & 1.0996 & 1.0758 & 1.0727 & 1.0778 & 1.0864 \\
& 70 & 1.1315 & 1.1175 & 1.1012 & 1.0772 & 1.0740 & 1.0792 & 1.0877 \\
\hline
\end{tabular}

Table 5. Annual $\mathrm{CO}_{2}$ emission for single building under Different $\mathrm{PV}$ and $\mathrm{HP}$ capacity $\left(\times 10^{4} \mathrm{~kg} / \mathrm{year}\right)$.

\begin{tabular}{ccccccccc}
\hline & \multicolumn{8}{c}{ HP Capacity $(\mathbf{k W})$} \\
\hline & & $\mathbf{0 . 5}$ & $\mathbf{1}$ & $\mathbf{5}$ & $\mathbf{1 0}$ & $\mathbf{2 0}$ & $\mathbf{2 5}$ & $\mathbf{3 0}$ \\
\cline { 2 - 9 } & 5 & 2.088 & 2.054 & 2.009 & 1.923 & 1.891 & 1.865 & 1.852 \\
& 10 & 2.041 & 2.008 & 1.963 & 1.876 & 1.845 & 1.818 & 1.806 \\
PV Capacity $\left(\mathrm{m}^{2}\right)$ & 20 & 1.952 & 1.919 & 1.874 & 1.787 & 1.756 & 1.730 & 1.717 \\
& 30 & 1.869 & 1.836 & 1.791 & 1.704 & 1.673 & 1.647 & 1.634 \\
& 50 & 1.708 & 1.674 & 1.629 & 1.542 & 1.511 & 1.485 & 1.472 \\
& 60 & 1.630 & 1.596 & 1.551 & 1.464 & 1.432 & 1.406 & 1.393 \\
& 65 & 1.554 & 1.520 & 1.475 & 1.387 & 1.356 & 1.330 & 1.317 \\
& 70 & 1.482 & 1.448 & 1.402 & 1.315 & 1.283 & 1.257 & 1.244 \\
\hline
\end{tabular}


In order to obtain an optimal value with the least amount of computation, around the global area of PV/T and PV system around $65 \mathrm{~m}^{2}$, several different PV/T to PV proportions are calculated. The result is shown in Table 6. The optimal capacity of PV/T and PV system is when the capacity of $\mathrm{PV}$ is $36 \mathrm{~m}^{2}$ and $\mathrm{PV} / \mathrm{T}$ is $30 \mathrm{~m}^{2}$. Compared to original system present in Tables 4 and 5, 2.4\% cost and $3.24 \% \mathrm{CO}_{2}$ emission will be saved this system.

Table 6. Energy hub Performance of different PV and PV/T capacity.

\begin{tabular}{|c|c|c|c|c|c|c|c|}
\hline $\begin{array}{l}\text { PV Capacity } \\
\qquad\left(\mathrm{m}^{2}\right)\end{array}$ & $\begin{array}{c}\text { PV/T Capacity } \\
\left(\mathbf{m}^{2}\right)\end{array}$ & $\begin{array}{c}\text { Global PV Area } \\
\left(\mathrm{m}^{2}\right)\end{array}$ & $\begin{array}{c}\text { Cost } \\
\left(\times 10^{4} \text { Euro/Year }\right)\end{array}$ & $\begin{array}{c}\text { Electricity } \\
\text { Consumption } \\
\left(\times 10^{4} \mathrm{kWh} / \text { year }\right)\end{array}$ & $\begin{array}{c}\mathrm{CO}_{2} \text { Emissions } \\
\left(\times 10^{4} \mathrm{~kg} / \text { Year }\right)\end{array}$ & $\begin{array}{l}\text { PVT Generation } \\
\text { (kWh/Year) }\end{array}$ & $\begin{array}{c}\text { HP Electricity } \\
\text { Consumption } \\
\left(\times 10^{3} \mathrm{kWh} / \text { Year }\right) \\
\end{array}$ \\
\hline \multirow{3}{*}{28} & 20 & 48 & 1.0573 & 5.40 & 1.60 & 118.9 & 3.45 \\
\hline & 24 & 52 & 1.0532 & 4.80 & 1.43 & 142.7 & 3.43 \\
\hline & 30 & 58 & 1.0473 & 4.60 & 1.37 & 178.3 & 3.39 \\
\hline \multirow{3}{*}{30} & 20 & 50 & 1.0567 & 4.85 & 1.44 & 118.9 & 3.45 \\
\hline & 24 & 54 & 1.0528 & 4.72 & 1.41 & 142.7 & 3.43 \\
\hline & 30 & 60 & 1.0471 & 4.52 & 1.35 & 178.3 & 3.39 \\
\hline \multirow{3}{*}{36} & 20 & 56 & 1.056 & 4.71 & 1.40 & 118.9 & 3.45 \\
\hline & 24 & 60 & 1.0523 & 4.58 & 1.37 & 142.7 & 3.43 \\
\hline & 30 & 66 & 1.047 & 4.38 & 1.31 & 178.3 & 3.39 \\
\hline \multirow{3}{*}{40} & 20 & 60 & 1.0556 & 4.54 & 1.36 & 118.9 & 3.45 \\
\hline & 24 & 64 & 1.0521 & 4.41 & 1.32 & 142.7 & 3.43 \\
\hline & 30 & 70 & 1.0475 & 4.22 & 1.27 & 178.3 & 3.39 \\
\hline \multirow{3}{*}{42} & 20 & 62 & 1.0555 & 4.49 & 1.34 & 118.9 & 3.45 \\
\hline & 24 & 66 & 1.0522 & 4.36 & 1.31 & 142.7 & 3.43 \\
\hline & 30 & 72 & 1.0478 & 4.17 & 1.25 & 178.3 & 3.39 \\
\hline \multirow{3}{*}{48} & 20 & 68 & 1.0556 & 4.38 & 1.31 & 118.9 & 3.45 \\
\hline & 24 & 72 & 1.0526 & 4.26 & 1.28 & 142.7 & 3.43 \\
\hline & 30 & 78 & 1.0488 & 4.07 & 1.23 & 178.3 & 3.39 \\
\hline
\end{tabular}

\section{Conclusions}

In this work, a multi-variable energy hub model has been designed for a residential building. Besides the fundamental elements such as main grid, natural gas net and gas boiler, heat pump and photovoltaic panel are considered in the initial energy hub system. Secondly, next, the optimal proportion between PV system and PV/T system has been considered. The efficiency of the electrical and thermal generation of both systems (PV and PV/T) are considered variable. The results show that the optimal scheduling method is beneficial to improve energy utilization efficiency and the practical application of renewable energy, reducing greenhouse gas emissions.

\section{References}

1. Favre-Perrod, P. A vision of future energy networks. In Proceeding of the Power Engineering Society Inaugural Conference and Exposition in Africa. Durban, South Africa, 11-15 July 2006; pp. 13-17.

2. Setlhaolo, D.; Sichilalu, S.; Zhang, J. Residential load management in an energy hub with heat pump water heater. Appl. Energy 2017, 208, 551-560.

3. Sharif, A.; Almansoori, A.; Fowler, M.; Elkamel, A.; Alrafea, K. Design of an energy hub based on natural gas and renewable energy sources. Int. J. Energy Res.2014, 38, 363-373.

4. Maniyali, Y.; Almansoori, A.; Fowler, M.; Elkamel, A. Energy Hub Based on Nuclear Energy and Hydrogen Energy Storage. Ind. Eng. Chem. Res. 2013, 52, 7470-7481.

5. Pazouki, S.; Haghifam, M.R. Optimal planning and scheduling of energy hub in presence of wind, storage and demand response under uncertainty. Int. J. Electr. Power Energy Syst. 2016, 80, 219-239.

6. Thanhtung, H.A.; Zhang, Y.; Thang, V.V.; Huang, J. Energy hub modeling to minimize residential energy costs considering solar energy and BESS. J. Mod. Power Syst Clean Energy 2017, 5, 389-399.

7. Zhang, X.; Shahidehpour, M.; Alabdulwahab, A.; Abusorrah, A. Optimal Expansion Planning of Energy Hub with Multiple Energy Infrastructures. IEEE Trans. Smart Grid 2017, 6, 2302-2311.

8. Vahid-Pakdel, M.J.; Nojavan, S.; Mohammadi-Ivatloo, B.; Zare, K. Stochastic optimization of energy hub operation with consideration of thermal energy market and demand response. Energy Convers. Manag. 2017, 145, 117-128.

9. Ma, T.; Wu, J.; Hao, L. Energy flow modeling and optimal operation analysis of the micro energy grid based on energy hub. Energy Convers. Manag. 2017, 133, 292-306. 
10. Sheikhi, A.; Ranjbar, A.M.; Safe, F. A novel method to determine the best size of CHP for an energy hub system. In Proceedings of the 2011 2nd International Conference on Electric Power and Energy Conversion Systems (EPECS), Sharjah, United Arab Emirates, 15-17 November 2011; pp. 1-7.

11. Wang, Y.; Hou, K.; Jia, H.; Mu, Y.; Zhu, L.; Li, H.; Rao, Q. Decoupled Optimization of Integrated Energy System Considering CHP Plant Based on Energy Hub Model. Energy Procedia 2017, 142, 2683-2688.

12. Wang, H.; Zhang, H.; Gu, C.; Li, F. Optimal design and operation of CHPs and energy hub with multi objectives for a local energy system. Energy Procedia 2017, 142, 1615-1621.

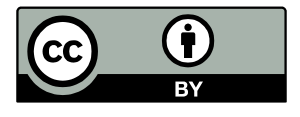

(C) 2018 by the authors. Licensee MDPI, Basel, Switzerland. This article is an open access article distributed under the terms and conditions of the Creative Commons Attribution (CC BY) license (http://creativecommons.org/licenses/by/4.0/). 